\title{
Assessing subspecies status of leopards (Panthera pardus) of northern Pakistan using mitochondrial DNA
}

\author{
Muhammad Asad ${ }^{\text {Corresp., } 1}{ }^{1}$, Francesco Martoni $^{2}$, James G Ross ${ }^{1}$, Muhammad Waseem ${ }^{3}$, Fakhar-i- Abbas ${ }^{4}$, Adrian M \\ Paterson $^{1}$ \\ ${ }^{1}$ Department of Pest-management and Conservation, Faculty of Agriculture and Life Science, Lincoln University, Lincoln, Canterbury, New Zealand \\ 2 AgriBio Centre for AgriBioscience, Agriculture Victoria Research, Bundoora, Victoria, Australia \\ 3 World Wide Fund for Nature (WWF), Islamabad, Pakistan \\ 4 Bioresource Research Centre, Islamabad, Pakistan \\ Corresponding Author: Muhammad Asad \\ Email address: muhammad.asad@lincolnuni.ac.nz
}

Despite being classified as critically endangered, little work has been done on leopard protection in Pakistan. Once widely present throughout this region, leopards are now sparsely distributed, and possibly extinct, from much of their previously recorded habitat. While leopards show morphological and genetic variation across their species range worldwide, resulting in the classification of nine different subspecies, the leopard genetic structure across Pakistan is unknown, with previous studies including only a very limited sampling. To clarify the genetic status of leopards in Pakistan we investigated the sequence variation in the subunit 5 of the mitochondrial gene NADH from 43 tissue samples and compared it with 238 sequences available from online databases.

Phylogenetic analysis clearly separates the Pakistani leopards from the African and Arabian clades, confirming that leopards from Pakistan are members of the Asian clade. Furthermore, we identified two separate subspecies haplotypes within our dataset: $P$. $p$. fusca $(\mathrm{N}=23)$ and P. p. saxicolor $(\mathrm{N}=12)$. 
1

2

3

4

5

6 Muhammad Asad $^{1 *}$, Francesco Martoni², James G. Ross ${ }^{1}$, Muhammad Waseem ${ }^{3}$, Fakhar-I-

\section{Assessing subspecies status of leopards (Panthera pardus) of northern Pakistan using mitochondrial DNA.}

Abbas $^{4}$, Adrian. M. Paterson ${ }^{1}$

81 Department of Pest-management and Conservation, Faculty of Agriculture and Life Science,

9 Lincoln University, Ellesmere Junction Road/Springs Road, PO Box 85084, Canterbury, New

10 Zealand.

112 Agriculture Victoria Research, AgriBio Centre, 5 Ring Road, Bundoora 3083, Australia.

123 WWF Pakistan, Pakistan academy of science building, 3rd constitution avenue, G-5/II,

13 Islamabad, Pakistan.

144 Bioresource Research Centre, Islamabad, House No: 34, Bazaar Road G-6/4, 15 Islamabad, Pakistan.

16 Corresponding author

17 Muhammad Asad

18 masadj@yahoo.co.uk (MA)

19 Tel: 0064212065301 


\section{Abstract}

21 Despite being classified as critically endangered, little work has been done on leopard protection

22 in Pakistan. Once widely present throughout this region, leopards are now sparsely distributed,

23 and possibly extinct, from much of their previously recorded habitat. While leopards show

24 morphological and genetic variation across their species range worldwide, resulting in the

25 classification of nine different subspecies, the leopard genetic structure across Pakistan is

26 unknown, with previous studies including only a very limited sampling. To clarify the genetic

27 status of leopards in Pakistan we investigated the sequence variation in the subunit 5 of the

28 mitochondrial gene NADH from 43 tissue samples and compared it with 238 sequences available

29 from online databases. Phylogenetic analysis clearly separates the Pakistani leopards from the

30 African and Arabian clades, confirming that leopards from Pakistan are members of the Asian

31 clade. Furthermore, we identified two separate subspecies haplotypes within our dataset: P. $p$.

32 fusca $(\mathrm{N}=23)$ and $P$. p. saxicolor $(\mathrm{N}=12)$. 


\section{Introduction} they are present (Uphyrkina et al. 2001), including Pakistan (Sheikh \& Molur 2004). There are currently nine recognized subspecies of the common leopard (Uphyrkina et al. 2001) and two out of these, African (P. p. pardus) and Indian (P. p. fusca), are considered "near threatened", while the rest are classified as "critically endangered", "endangered" and "near threatened to endangered" (Sheikh \& Molur 2004; Stein et al. 2016).

Globally, leopard subspecies recognition is based on genetic, morphological and geographical information (Jacobson et al. 2016). However, leopards show high genetic and morphological variation across their range and in many cases genetic patterns do not align with the geographical variation recorded for previously defined subspecies (Uphyrkina et al. 2001). Therefore, the study of the genetic structure of leopard populations is considered vital for a better understanding of both subspecies and population subdivision and, consequently, for their conservation (Khorozyan et al. 2006; Sugimoto et al. 2013). Molecular studies have contributed significantly in the field of conservation for many other elusive cat species, such as snow leopards, lions and tigers (Dubach et al 2005; Wei et al. 2008; Bhavanishankar et al. 2013). Similarly, in the case of leopards, genetic analyses increasingly provide taxonomic guidance for subspecies identification (Uphyrkina et al. 2001; Arif et al. 2011; Sugimoto et al. 2014).

1 Conservation and management of leopards are difficult tasks made even harder by a general lack of understanding of the broad geographic ranges and adaptability of this species, factors that make leopards more detectable than their actual numbers would warrant (Jacobson et al 2016). These detections increase the misconception that leopards are not as severely endangered as they 
55

56

57

58

59

60

61

62

63

64

actually are (Jacobson et al. 2016). In Pakistan, while leopards are known to be present, there is no information on their distribution, number or subspecies. Based on the severe decline rate of leopard populations in Asia, the Pakistani population is likely to be fragmented and with depleted genetic variation (Dutta et al. 2013; Jacobson et al. 2016). Asian leopards have lost around 83$87 \%$ of their former range, compared with a 48-67\% decline in Africa (Sheikh \& Molur 2004; Khorozyan et al. 2006; Laguardia et al. 2015; Jacobson et al. 2016). It is, therefore, essential to identify the subspecies present in Asia to prevent further loss of biodiversity (Arif et al. 2011). the western edge of the Indus Basin and the upper Indus valley of Kohistan (Frodin 1984). In the past, this biogeographic disjunction has served as a geographical limit to two of the main standard floras for Southwest and South Asia: Boissier's Flora Orientalis (1867-1888) and Hooker's Flora of British India (1872-1897).

Four leopard subspecies have been suggested as present in Pakistan: Panthera pardus fusca, P. p. saxicolor, P. p. sindica, and P. p. millardi. These subspecies were identified based solely on morphological characters, such as unique coat pattern, coloration, fur length, body size and skull size (Pocock 1930a and b; Roberts et al. 1977). However, these characters vary in different environmental conditions and may lead to subspecies misidentification (Uphyrkina et al. 2001). A morphological analysis of Pakistani leopard skulls (Khorozyan et al. 2006) suggested the presence of only two subspecies: $P . p$. sindica from Baluchistan, similar to the subspecies population in southern Iran, and P. p. millardi from Kashmir, similar to the population present in India. A recent study based on the global geographic distribution patterns suggested that the subspecies present in the region were P. p. saxicolor and P. p. fusca (Jacobson et al. 2016). The only genetic sample collected from a Pakistani leopard in the wild was from a single individual in 
78 the region of Baluchistan, and identified as the subspecies P. p saxicolor (Uphyrkina et al. 2001).

79 This study aims to better understand the genetic structure of the leopard in Pakistan, identify the

80 subspecies present, and establish baseline information for future monitoring. We present results

81 based on more than 40 leopard samples from Pakistan and we investigate genetic variation in the

82 mtDNA, targeting the subunit 5 of the NADH gene (NADH-5), following the approaches of

83 previous studies (e.g. Uphyrkina et al. 2001; Farhadinia et al. 2015; Anco et al. 2018). The choice

84 of mtDNA was based on the good performances and wide adoption for felids (e.g. Jae-Heup et al.

85 2001; Luo et al. 2004; Barnett et al. 2006; Havird \& Sloan 2016). In particular, the choice of

86 NADH-5 gene was based on the good performance of this gene in subspecies delimitation for

87 carnivores, showing a higher mutation rate for this group (e.g. Lopez et al. 1997). Furthermore,

88 considering the general use of NADH-5 in leopard studies (e.g. Uphyrkina et al. 2001; Farhadinia

89 et al. 2015; Anco et al. 2018), we focused on this gene also for continuity with previous works, by

90 generating sequences that can be added to previous datasets. More specifically, Our samples are

91 mostly sourced from the northern region of Pakistan (Galyat, Murree, and Aazad Kashmir) with a

92 single specimen from Baluchistan. This research will add to the scarce existing scientific

93 knowledge of species assessment in Pakistan, helping prioritize the conservation efforts for

94 leopards, and will consequently contribute to the international works on felids.

95

96 Materials and methods

97 Sample collection

98 Animal ethics committee approval AEC2017-02 was obtained prior to the experiment. A total of

9949 samples of leopard skin tissue was initially obtained for this study. Most of these samples were

100 from the northern region of Pakistan, where the leopard population is considered stable (Shehzad 
101 et al. 2014) (Fig. 1). Of these, 22 leopards were killed by communities in retaliation for attacks,

102 including seven killed during the period of this study. Two leopards had died of natural causes, the

103 rest of the leopard mortality is unknown. Eighteen samples were provided by the Bioresource

104 Research Centre of Islamabad (Pakistan) and had been used in a previous study (Bebi et al. 2015).

105 Nine tissue samples were provided by Wildlife Department Khyber Pakhtunkhwa and 15 samples

106 from the World Wide Fund for Nature Pakistan (Fig. 1). The majority of the samples were collected

107 from two different areas: the Azad Jamu Kashmir and the Galyat region. Additionally, two samples

108 were provided by BRC from Baluchistan and Sukkur.

\section{DNA extractions and amplifications}

109 All tissues were preserved in 70\% ethanol until DNA extraction and amplification.

110 In a preliminary analysis conducted at the Bio Resource Research Centre facilities of Islamabad

111 (Pakistan), DNA was extracted from three samples using the QIA amp DNA Mini Kit (QIAGEN)

112 following the manufacturer's instructions while the remaining samples were sent to Macrogen Inc.

113 (Seoul, Korea) for DNA extraction and polymerase chain reaction (PCR) optimization. Four 114 samples were discarded because of a lack of detailed information on their origin, while two 115 samples were not sequenced due to possible contamination during the transport.

116 Using the full mitochondrial sequence of leopard available on the National Center for 117 Biotechnology Information (NCBI) database (accession number EF551002.1); two set of primers 118 pairs (F/RL2 and FL2/RL4; Table 1) were designed to target two overlapping regions of the 119 subunit 5 of the NADH mitochondrial gene. These corresponded to nucleotide positions 1263212013242 of the mitochondrial DNA of leopards. Primer design, PCR amplification, PCR 121 purifications and sequencing were outsourced to Macrogen Inc. (Seoul, Korea) and were carried 122 out following the methods of previous studies (Uphyrkina et al. 2001; Farhadinia et al. 2015). 
123 Sample preparation and DNA extraction were conducted in a laminar flow hood in an area isolated

124 from other samples to prevent any contamination. Genomic DNA was isolated using InstaGene 125 Matrix (Bio-Rad Laboratories; USA) and MG Tissue SV (Doctor protein inc, Korea). PCR was 126 run for 35 cycles, with 5 min pre-denaturation at $95{ }^{\circ} \mathrm{C}$ followed by denaturation at $94{ }^{\circ} \mathrm{C}$ for 30 $127 \mathrm{sec}$, and $30 \mathrm{sec}$ annealing at $50{ }^{\circ} \mathrm{C}$, and by 1 min extension at $72{ }^{\circ} \mathrm{C}$. Products were then checked 128 in $1.5 \%$ agarose gel, running for $20 \mathrm{~min}$ at $300 \mathrm{~V}, 200 \mathrm{~A}$. Purification was carried out with 129 multiscreen filter plate (Millipore Sigma; USA). Each PCR product obtained was sequenced (both 130 forward and reverse) by Macrogen Inc. (Seoul, Korea) using Sanger sequencing technologies.

131 Data analysis

132 A total of 43 samples produced viable sequences. Sequencing data is available at NCBI GenBank via accession numbers MK425702-MK425744. This data is also available as a Supplemental File.

134 The software MEGA 7 (Kumar et al. 2016) was used to visually inspect the electropherograms, to 135 align the sequences and generate a pairwise distance matrix that was then used to identify the 136 different haplotypes.

137 In order to compare the haplotypes obtained here with other sequences belonging to the species

138 Panthera pardus, all 238 sequences present on the GenBank database (to the month of August 139 2018) were obtained (Table 2) and aligned with those collected in this study together with 140 sequences from snow leopards, tigers and lions as outgroups (Table 2). We used the software 141 MEGA X (Kumar et al., 2018) to identify the best model of nucleotide substitution based on the 142 Bayesian Information Criterion (BIC). This reported the Kishino and Yano (HKY) $+\mathrm{G}$ model of 143 nucleotide substitution (gamma distribution with five rate categories) as the best model, as 144 previously found elsewhere (Farhadinia et al. 2015). Additionally, the Kimura-2-parameters (K2P) 145 substitution model was also tested here. A maximum likelihood (ML) NADH 5 gene tree was 
146 generated using MEGA X, setting the bootstrap to 10000 replicates and using both the substitution

147 models. PopArt (Leigh \& Bryant 2015) was used to construct a Median Joining haplotype network

$148(\varepsilon=0)$ of all the sequences from Asian leopards.

\section{$149 \underline{\text { Results }}$}

150 We used 43 NADH 5 sequences for the final stage of the analysis. When these were aligned to the 151238 leopard sequences available on GenBank, the ML analysis grouped all Pakistan sequences 152 within the Asian leopards, well separated (with a bootstrap of 85\% using a K2P model and 52\% using a HKY+G model) from both African and Arabian leopards (Fig. 2). While the new sequences obtained in this study could be separated from those of African leopards and attributed to the Asian leopards, the ML analysis showed low genetic variation within the two groups, highlighted by very low bootstrap values throughout the tree (Fig. 2). After confirming that all our sequences belonged to Asian leopards, further analysis aimed to understand the relationships of our samples to the different subspecies of this group. In order to measure genetic variation between our sequences and within the Asian leopards, a haplotype network analysis was performed on a total of 35 sequences (Accession numbers MK425702-MK425736). For this analysis, eight samples where discarded due to shorter length of the sequence. Hence, this analysis included 35 samples from this dataset, all the sequences of Asian leopards available on GenBank, a subset of 13 sequences of African leopards and one sequence from an Arabian leopard (Fig. 3). The sequences presented here identified three distinct haplotypes (Fig. 1, Fig. 3). The first haplotype (A) included 23 samples and was identical to two sequences previously identified as Panthera pardus fusca (Accession number: AY035274.1) and Panthera pardus orientalis (Accession number: HQ185550.1) (Fig. 3). The second haplotype (B) included 11 samples with identical sequences to 
169 sample (Fig. 3) and was not the same as any previously identified haplotype. The haplotype

170 diversity amongst the Pakistani samples was based on three segregation sites with a nucleotide

171 variation ranging between 0.003 and 0.006 (Table 3).

\section{Discussion}

173 Despite the limitations of our sample size, this study generated the first genetic datasets for leopard 174 populations in Pakistan. The genetic diversity of leopards from the northern region of Pakistan was

175 determined here based on 43 specimens. As expected, all the samples included in this study 176 clustered within the Asian leopard clade. However, the haplotype network analysis highlighted the 177 presence of three different haplotypes. We recorded a similar nucleotide diversity, ranging 178 between 0.003 and 0.006 , to that reported for different leopard subspecies in other studies 179 (Uphyrkina et al. 2001; Farhadinia et al. 2015).

The genetic variation of the Pakistan leopard samples was not consistent with their being a single subspecies in Pakistan, whether existing or novel. Eleven samples (Haplotype B) grouped with sequences of Panthera pardus saxicolor and are here attributed to this subspecies. Similarly, the haplotype represented by a single specimen (Haplotype C) grouped closely to the other $P . p$. saxicolor haplotypes and is here attributed to this subspecies, as well. The main Pakistan haplotype (Haplotype A), including 23 samples, grouped with two separate sequences previously recorded from two studies in Caucasus (Uphyrkina et al. 2001; Rozhnov et al. 2011). These sequences (HQ185550.1 and AY035274.1) are identical to each other although they were named differently: respectively P.p. orientalis, and P. p. fusca. Based on the similarities between our sequences and the other haplotypes of $P . p$. fusca, however, we are inclined to consider them as belonging to this subspecies. Similarly, considering the genetic distance between this single sequence of P.p. orientalis obtained from GenBank and the other sequences of the same subspecies, we consider its 
192 attribution to orientalis an incorrect identification. However, it is possible that the subspecies $P$.

193 p. fusca has a large amount of genetic variation, to the point that it could subsume some of the 194 other subspecies. In order to confirm this hypothesis, additional samples from this subspecies are 195 required, together with additional samples of $P$. p. orientalis, together the analysis of additional 196 gene regions.

197 This analysis is consistent with Uphyrkina and colleagues who grouped the subspecies $P$. pardus sindica and P. pardus millardi with the Persian and Indian leopards (Uphyrkina et al. 2001). These two subspecies, first described by Pocock (1930) based on morphometric characters only, were retained by Khorozyan and colleagues (2006). On the other hand, all the samples collected for this study likely belong to two subspecies of Panthera pardus: P. p. fusca (Indian) and P. p. saxicolor (Persian), highlighting a higher than expected subspecies diversity for the area that we examined. In fact, our findings are not consistent with the assumption that the river Indus separates the saxicolor and fusca subspecies, as was hypothesised in previous studies (Khorozyan et al. 2006; Jacobson et al. 2016). The vast majority of our samples (except those from Baluchistan, Nizampur and Sakher) belonged to the northern region of the Indus, reporting the presence of both $P . p$. saxicolor and P. p. fusca in this region, where only latter was hypothesised to live.

The limited number of samples used for this study (especially from the regions of Baluchistan, and Nizampur) most certainly does not fully reflect the subpopulation of these regions. Therefore, further studies are likely to discover an even higher diversity in subspecies than reported here, as already confirmed from Baluchistan, where subpopulation closely related to the Persian leopard are known to be present (Jacobson et al. 2016). 
215 ecological overlap of the two leopard subspecies recorded here and it provides suitable conditions

216 for a high level of gene flow between them. Random mating in the expanded region may support

217 the hypothesis that overall, the Asian population is panmictic and it presents a moderate level of

218 genetic variation (Fig. 2). Panmixis assumes that there are no mating restrictions and, for this to

219 happen, gene flow between leopard sub-populations and sub-species has to happen across all their

220 habitat in Asia. Leopards are known to travel long distances, e.g. $194 \mathrm{~km}$ (Fattebert et al. 2013),

221 and have the largest home range recorded of large cats, e.g. $670 \mathrm{~km}^{2}$ (Hunter, 2011) in central Iran.

222 Pakistan assumes a role in leopard conservation by providing a contact zone for the

223 subspecies $P$. p. fusca and P. p. saxicolor, subspecies considered endangered (P. p. saxicolor) or

224 near threatened (P. p. fusca). The overlapping distribution of these two subspecies provides an

225 impetus to extend full protection to leopards beyond the limits of regional parks and reserves, over

226 all the Pakistani territory.

227

The primary constraint in the conservation of leopards in Pakistan is a lack of detailed

information, such as presence/absence of each subspecies within the highly fragmented habitat.

While the information obtained in this study enables a better understanding of leopard distribution in the areas monitored, further work is required for the more remote regions. Unfortunately, the political instability of some of these regions, together with a widespread lack of financial resources remain a key challenge for sustainable management and conservation of leopards. In addition, away from many habitats, such as the Kirthar National Park where they have been reported as a locally extinct (Khan et al. 2013). 
238 With the present work, we have highlighted the co-existence of multiple subspecies in the same

239 area in the north of Pakistan. In order to compare these results with other areas of the country, we

240 suggest that further studies focusing on the presence-absence of leopards in Baluchistan, Sindh

241 and in the areas of Punjab and Khyber Pakhtunkhwa are urgently required. In fact, obtaining

242 genetic information from these areas will complement the knowledge now available and enable a

243 better understanding of distribution and ecology of leopards, not only in Pakistan but also

244 worldwide.

246 Acknowledgements

247 We thank Anthony Caragiulo and an anonymous reviewer for helpful comments and suggestions

248 on a previous version of this manuscript that helped improving the quality of this work. We are

249 grateful to the Wildlife Department Khyber Pakhtunkhwa Pakistan, Bioresource Research Centre

250 Islamabad, and WWF-Pakistan for providing samples to conduct this research. We thank all the

251 staff at the Wildlife Department Khyber Pakhtunkhwa and WWF-Pakistan for facilitating the

252 study. We also greatly appreciate the assistance provided by Sajid Hussain for collecting and

253 preserving tissue samples from dead leopards killed by communities in retaliation for previous

254 attacks.

\section{References}

256

257

258

259

260

261

262

Anco C, Kolokotronis SO, Henschel P, Cunningham SW, Amato G, \& Hekkala E. 2018. Historical mitochondrial diversity in African leopards (Panthera pardus) revealed by archival museum specimens. Mitochondrial DNA A DNA Mapping Sequencing and Analysis, 29(3): 455-473.

Arif IA, Khan HA, Bahkali AH, Al Homaidan AA, Al Farhan AH, Al Sadoon M, \& Shobrak M. 2011. DNA marker technology for wildlife conservation. Saudi Journal of Biologial Sciences, 18(3): 219-225. 
263

264

265

266

267

268

269

270

271

272

273

274

275

276

277

278

279

280

281

282

283

284

285

286

287

288

289

290

291

292

293

294

295

296

297

298

299

300

301

302

303

304

305

306

Barnett R, Yamaguchi N, Barnes I \& Cooper A. 2006. Lost populations and preserving genetic diversity in the lion Panthera leo: Implications for its ex situ conservation. Conservation Genetics, 7(4), 507-514.

Bebi SS, Rehman A, Minhas RA, Andleeb S, Awan MS, \& William K. 2015. Genetic diversity among common leopards inhabiting Azad Jammu and Kashmir, Pakistan. The Journal of Animal \& Plant Sciences, 25(2): 423-428.

Bhavanishankar M, Reddy PA, Gour DS, \& Shivaji S.2013. Validation of non-invasive genetic identification of two elusive, sympatric, sister-species-tiger (Panthera tigris) and leopard (Panthera pardus). Current Science, 1063-1067.

Boissier PE. 1867-1888. Flora Orientalis. 6 vols. H. Georg, Geneva.

Dubach, J, Patterson, BD, Briggs MB, Venzke K, Flamand J, Stander P, Scheepers L, Kays RW. 2005. Molecular genetic variation across the southern and eastern geographic ranges of the African lion, Panthera leo. Conservation Genetics, 6(1): 15-24.

Dutta T, Sharma S, Maldonado JE, Wood TC, Panwar HS, \& Seidensticker J. 2013. Gene flow and demographic history of leopards (Panthera pardus) in the central Indian highlands. Evolutionary Applications, 6(6): 949-959.

Farhadinia MS, Farahmand H, Gavashelishvili A, Kaboli, M, Karami M, Khalili B, \& Montazamy S. 2015. Molecular and craniological analysis of leopard, Panthera pardus (Carnivora: Felidae) in Iran: support for a monophyletic clade in Western Asia. Biological Journal of the Linnean Society, 114(4): 721-736.

Fattebert J, Hunter L, Balme G, Dickerson T, \& Slotow R. 2013. Long-distance natal dispersal in leopard reveals potential for a three-country metapopulation. South African Journal of Wildlife Research,-24-month delayed open access 43(1): 61-67.

Frodin DG. 1984. Guide to Standard Floras of the World. Cambridge Univ. Press, Cambridge.

Havird JC \& Sloan DB. 2016. The roles of mutation, selection, and expression in determining relative rates of evolution in mitochondrial versus nuclear genomes. Molecular biology and evolution, 33(12), 3042-3053.

Hooker JD. 1872-1897. Flora of British India. 7 vols. Reeve, London.

Hunter L 2011. Carnivores of the World. Edition 2 Princeton University Press; Princeton; 256 pp.

Jacobson AP, Gerngross P, Lemeris JR Jr, Schoonover RF, Anco C, Breitenmoser-Wursten C, Durant SM, Farhadinia MS, Henschel P, Kamler JF, Laguardia A, Rostro-Garcia S, Stein AB, Dollar L. 2016. Leopard (Panthera pardus) status, distribution, and the research efforts across its range. PeerJ, 4, e1974.

Jae-Heup K, Eizirik E, O'Brien SJ \& Johnson WE. 2001. Structure and patterns of sequence variation in the mitochondrial DNA control region of the great cats. Mitochondrion, 1(3), 279-292.

Khorozyan I. 2014. Morphological variation and sexual dimorphism of the common leopard (Panthera pardus) in the Middle East and their implications for species taxonomy and conservation. Mammalian Biology, 79(6), 398-405.

Khorozyan I, Baryshnikov GF, \& Abramov AV. 2006. Taxonomic status of the leopard, Panthera pardus (Carnivora, Felidae) in the Caucasus and adjacent areas. Russian Journal of Theriology, 5(1): 41-52.

Kumar S, Stecher, G., \& Tamura K. 2016. MEGA7: Molecular Evolutionary Genetics Analysis Version 7.0 for Bigger Datasets. Molecular Biology and Evolution, 33(7): 1870-1874. 
307

308

309

310

311

312

313

314

315

316

317

318

319

320

321

322

323

324

325

326

327

328

329

330

331

332

333

334

335

336

337

338

339

340

341

342

343

344

345

346

347

348

349

350

351

352

Kumar S, Stecher G, Li M, Knyaz C, Tamura K. 2018. MEGA X: Molecular Evolutionary Genetics Analysis across Computing Platforms. Molecular Biology and Evolution, 35(6): $1547-1549$.

Laguardia A, Kamler JF, Li S, Zhang C, Zhou Z, \& Shi K. 2015. The current distribution and status of leopards Panthera pardus in China. Oryx, 51(1): 1-7.

Lei W, XiaoBing W, Zhu L, \& Jiang Z. 2011. Mitogenomic analysis of the genus Panthera. Science China. Life Sciences, 54(10): 917-930.

Leigh JW, \& Bryant D. 2015. Popart: full-feature software for haplotype network construction. Methods in Ecology and Evolution, 6(9): 1110-1116.

Lopez JV, Culver M, Stephens JC, Johnson WE, O’Brien SJ. 1997. Rates of nuclear and cytoplasmic mitochondrial DNA sequence divergence in mammals. Molecular Biology and Evolution 14: 277-286.

Luo S-J, Kim J-H, Johnson WE, Van Der Walt J, Martenson J, Yuhki N, Miquelle DG, Uphyrkina O, Goodrich JM, Quigley HB, Tilson R, Brady G, Martelli P, Subramaniam V, McDougal C, Hean S, Huang S-Q, Pan W, Karanth UK, Sunquist M, Smith JLD, O'Brien SJ. 2004. Phylogeography and genetic ancestry of tigers (Panthera tigris). PLoS biology, 2(12), e442.

Pocock RI. 1930 a. The panthers and Ounces of Asia. Journal of the Bombay Natural History Society, 34 (1);65-82.

Pocock RI. 1930 a. The panthers and ounces of Asia. Part II. The panthers of Kashmir, India and Ceylon. Journal of the Bombay Natural History Society, 34(2): 307-336.

Roberts TJ. 1977. The mammals of Pakistan. London: Ernest Benn Limited.xxvi, 361pp.

Ropiquet A, Knight AT, Born C, Martins Q, Balme G. 2015 Implications of spatial genetic patterns for conserving African leopards. Comptes Rendus Biologies, 338(11): 728-737.

Rozhnov VV, Lukarevsky V, \& Sorokin P. 2011. Use of molecular-genetics characteristics for reintroduction of leopard (Panthera pardus L., 1758) in the Caucasus. In Doklady Academii Nauk, 437: 280-285.

Shehzad W, Nawaz MA, Pompanon F, Coissac E, Riaz T, Shah SA \& Taberlet P. 2014. Forest without prey: livestock sustain a leopard Panthera pardus population in Pakistan. Oryx, 49(02), 248-253. doi:10.1017/s0030605313001026

Sheikh KM, \& Molur S. 2004. Status and Red List of Pakistan's mammals based on the Pakistan Mammal Conservation Assessment \& Management Plan. 312pp. IUCN Pakistan

Stein AB, Athreya V, Gerngross P, Balme G, Henschel P, Karanth U, Kamler JF, \& Laguardia. 2016. Panthera pardus. The IUCN red list of threatened species.

Sugimoto T, Aramilev VV, Kerley LL, Nagata J, Miquelle DG, \& McCullough D R. 2013. Noninvasive genetic analyses for estimating population size and genetic diversity of the remaining Far Eastern leopard (Panthera pardus orientalis) population. Conservation Genetics, 15(3): 521-532.

Sugimoto T, Gray TN Edward, Higashi S, \& Prum S. 2014. Examining genetic diversity and identifying polymorphic microsatellite markers for noninvasive genetic sampling of the Indochinese leopard (Panthera pardus delacouri). Mammalian Biology, 79(6): 406-408.

Uphyrkina O, Johnson WE, Quigley H, Miquelle D, Marke, L, Bush M, \& O'Brien SJ. 2001. Phylogenetics, genome diversity and origin of modern leopard, Panthera pardus. Molecular Ecology, 10(11): 2617-2633.

Wei L, Wu X, \& Jiang Z. 2008. The complete mitochondrial genome structure of snow leopard Panthera uncia. Molecular Biology Reports, 36(5): 871. 
353 Zhang W, Yue B, Wang X, Zhang X, Xie ZC, Liu N, Fu W, Yuan Y, Chen D, Fu D, Zhao B, Yin 354 Y, Yan X, Wang X, Zhang R, Liu J, Li M, Tang YQ, Hou R, \& Zhang Z. 2011. Analysis

355

356 of variable sites between two complete South China tiger (Panthera tigris amoyensis) mitochondrial genomes. Molecular Biology Reports, 38: 4257-4264. 


\section{Figure 1}

Sampling locations of Panthera pardus in the northern regions of Pakistan (Galyat and Azad Kashmir) .

The 35 samples included in the haplotype analysis are represented here. Red dots indicate samples belonging to haplotype $A$; blue squares are samples from haplotype $B$; and the single Yellow triangle indicates haplotype $C$. The different colours present in the map indicate the habitat where samples were found, highlighting the presence of natural reserves, national parks and forests. 

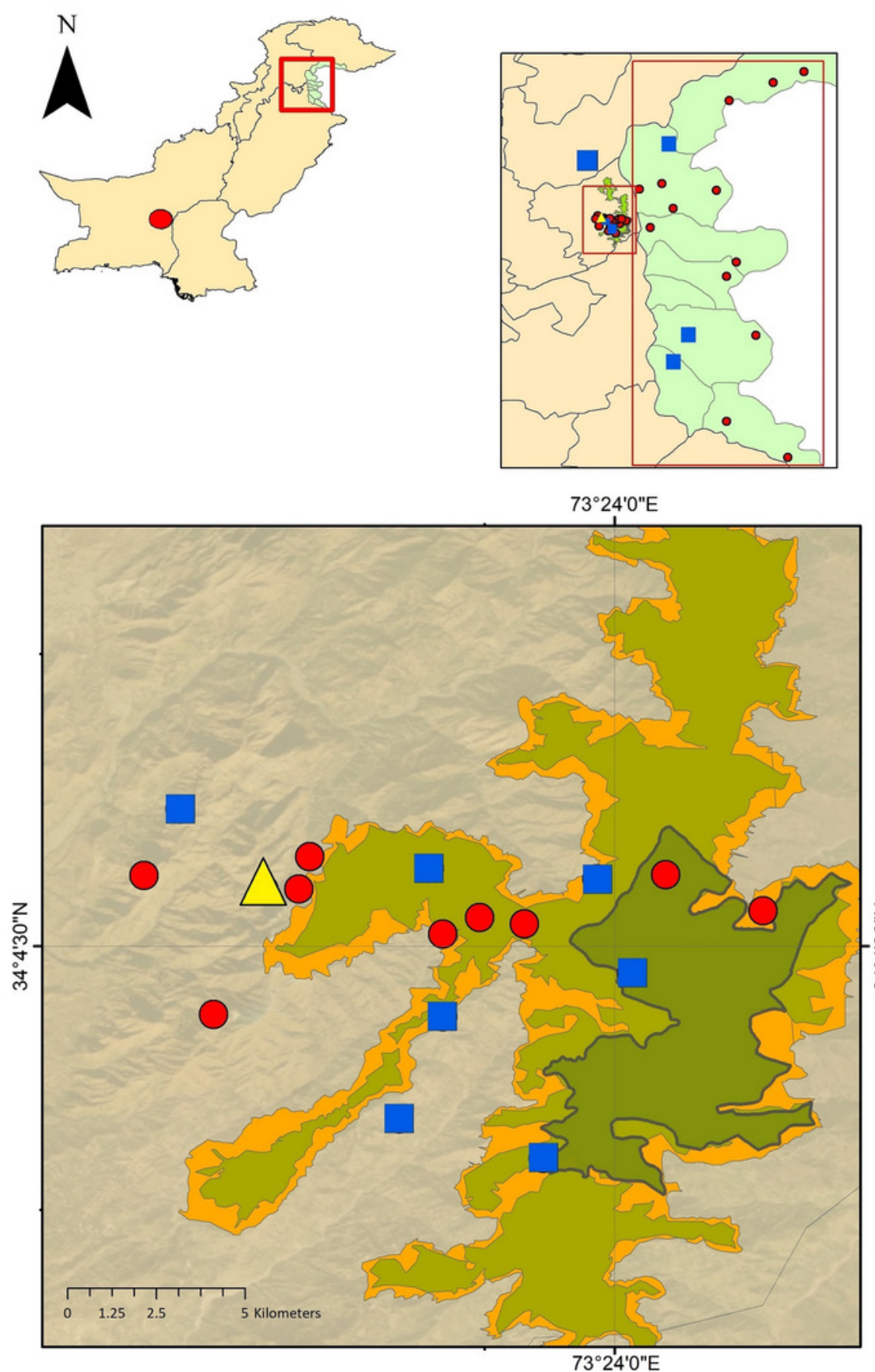

$73^{\circ} 24^{\prime} 0^{\prime \prime E}$

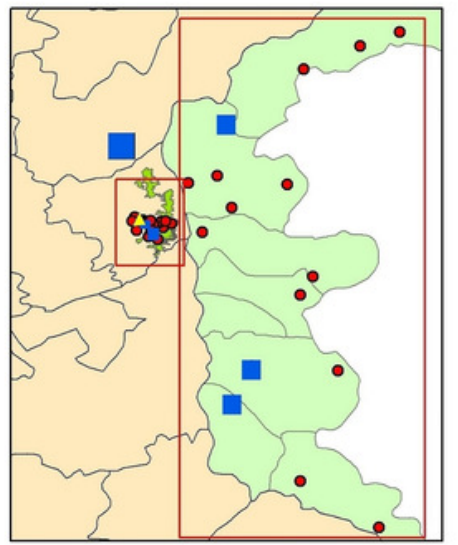

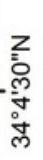

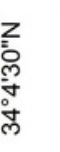

$73^{\circ} 30^{\prime} \mathrm{O} \mathrm{E} \quad 73^{\circ} 52^{\prime} 30$ "E $\quad 74^{\circ} 15^{\prime} \mathrm{O} \mathrm{E} \mathrm{E}$

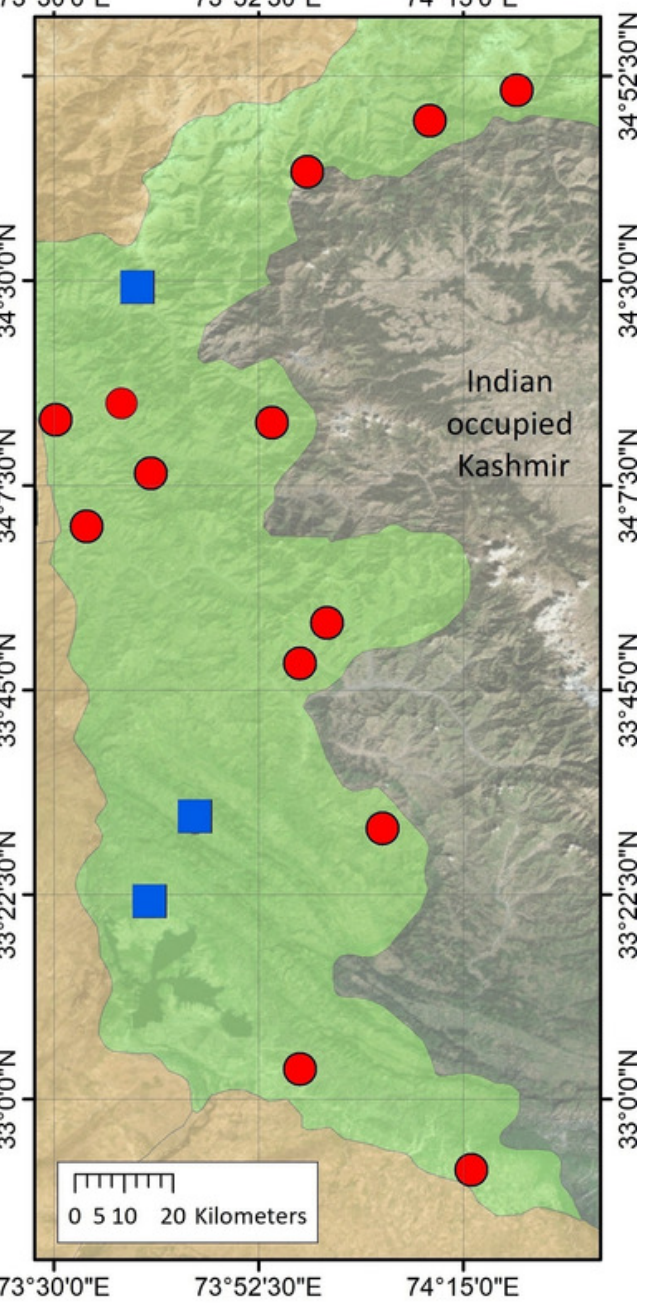

Legend

- Haplotype A

Haplotype B

Haplotype C

Reserved Forest

Ayubia National Park Guzara forest

Azad Kashmir 


\section{Figure 2}

Maximum likelihood NADH5 gene tree (10000 replicates, K2P model) of 273 sequences from across the globe.

The gene tree separates Asian leopards (green) from Africans (orange), with a bootstrap of 85\%.Outgroups are reported in grey.

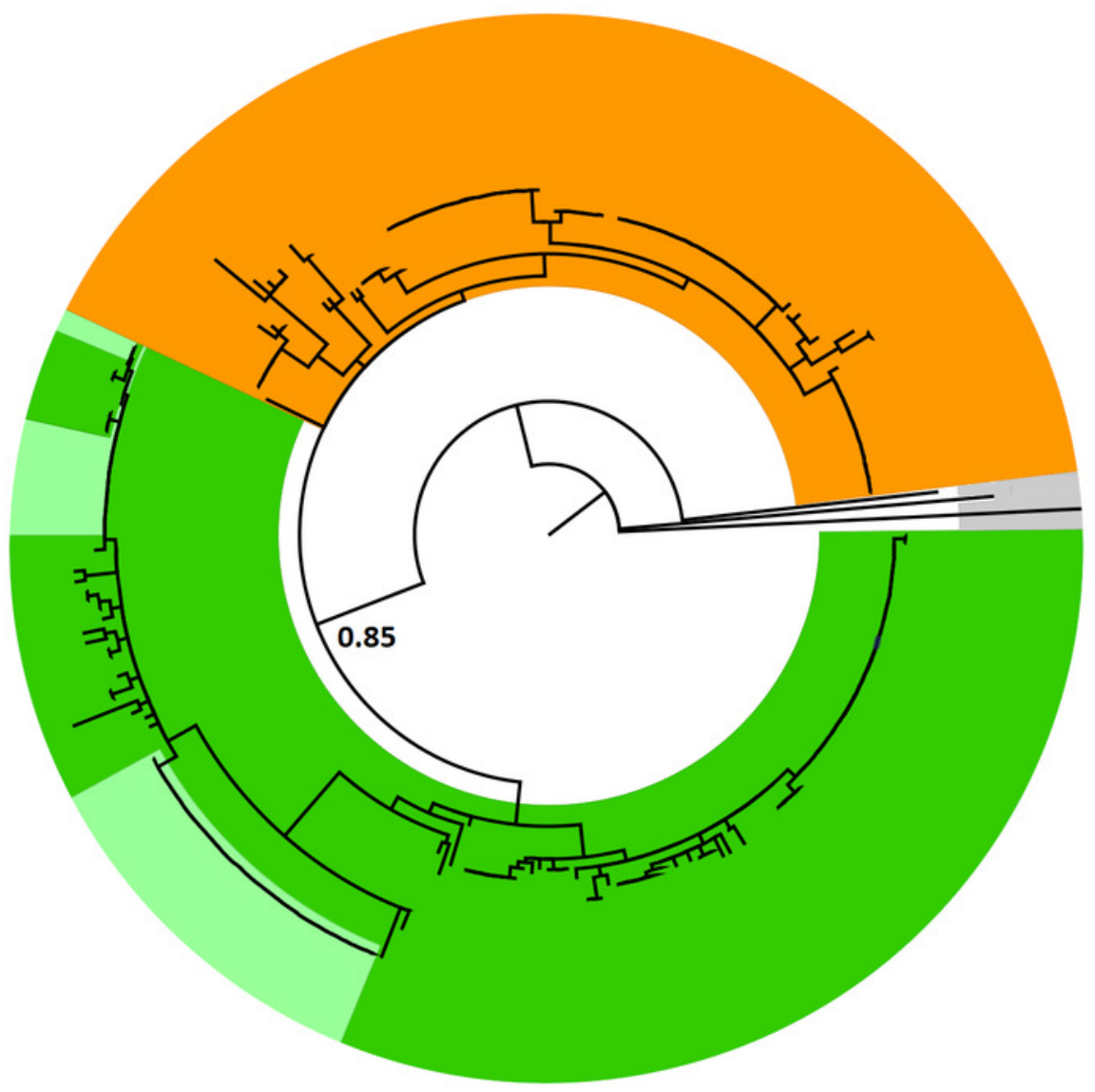

African leopards

Asian leopards

Present study

Outgroup 
Figure 3

Median joining network analysis of the Asian leopards.

The network includes 35 sequences of Pakistani leopards, 13 sequences from African leopards, a single sequence from a Persian leopard, and all the sequences from Asian leopards publicly available. Haplotypes are color-coded based on previous subspecies identification. Size of the circles represents the number of sequences with the same haplotype.

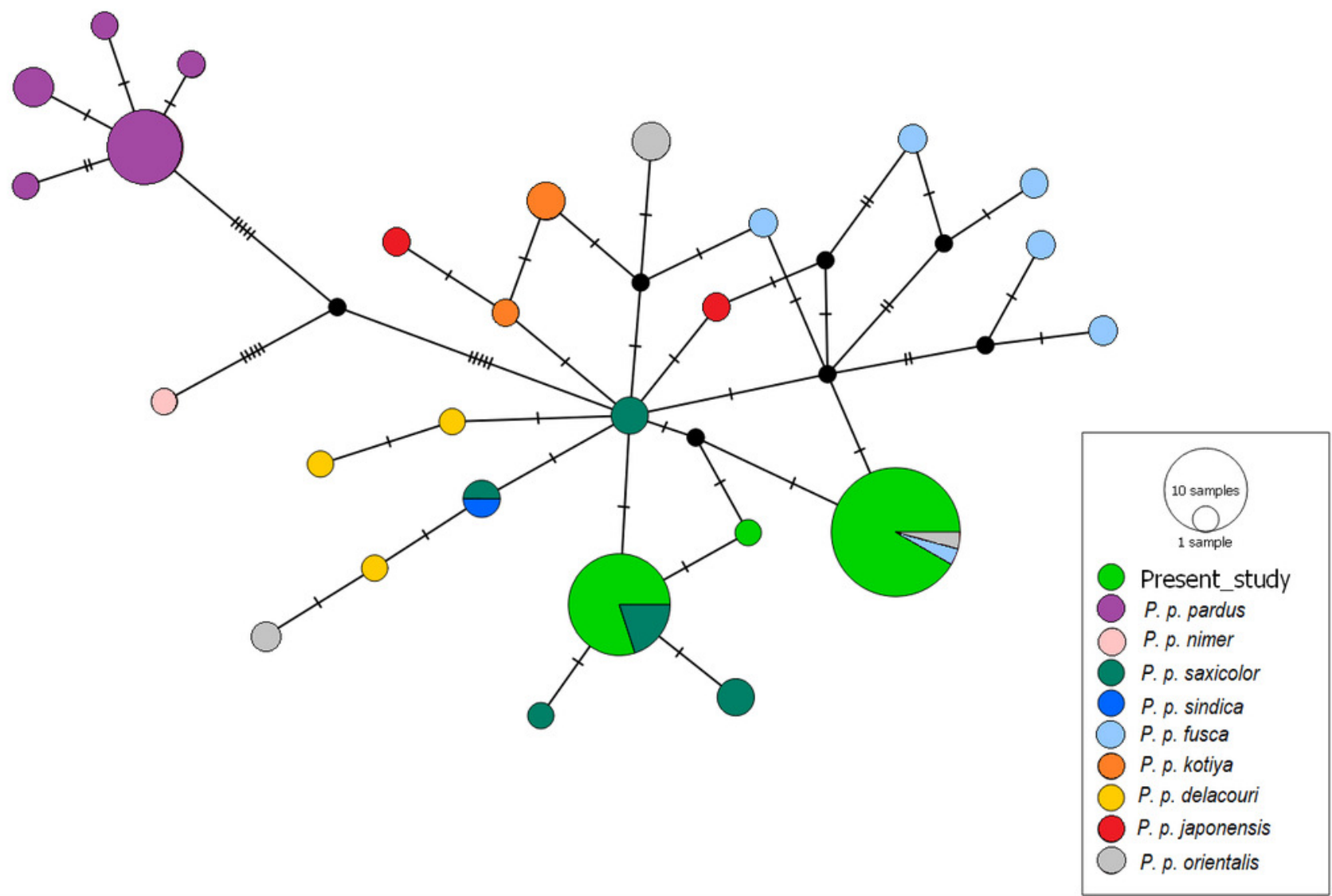




\section{Table 1 (on next page)}

Primers used for DNA isolation and amplification.

Name, direction and sequences of the primers designed for this study are reported. 
1 Table 1. Primers used for DNA isolation and amplification. Name, direction and sequences of the primers designed 2 for this study are reported.

\begin{tabular}{|l|l|l|}
\hline Primer Name & Direction & Sequence $\mathbf{( 5}^{\prime}$ to $\mathbf{3}^{\prime} \mathbf{)}$ \\
\hline F & Forward & GTGCAACTCCAAATAAAAG \\
\hline RL2 & Reverse & TAAACAGTTGGAACAGGTT \\
\hline FL2 & Forward & CGTTACATGATCGATCATAG \\
\hline RL4 & Reverse & TTAGGTTTTCGTGTTGGGT \\
\hline
\end{tabular}

3 


\section{Table 2 (on next page)}

Leopard sequences obtained from GenBank together with outgroups used in our study.

Accession numbers are reported with the number of sequences for each gene region per species and subspecies used in this work. Origin of the samples and original work publishing these sequences are reported. 
1 Table 2. Leopard sequences obtained from GenBank together with outgroups used in our study. Accession numbers are reported with the

2 number of sequences for each gene region per species and subspecies used in this work. Origin of the samples and original work publishing these

3 sequences are reported.

\begin{tabular}{|c|c|c|c|c|c|c|}
\hline Accession numbers & Sequences & Gene & Species & Subspecies & Sample Area & Reference \\
\hline KY292222.1 - KY292277.1 & 56 & NADH5 & $\begin{array}{l}\text { Panthera } \\
\text { pardus }\end{array}$ & Africans & Africa & Anco et al. 2018 \\
\hline JX559073.1 - JX559076.1 & 4 & NADH5 & P. pardus & Saxicolor & Iran & Farhadinia et al. (Unpublished) \\
\hline JF720187.1 - JF720319.1 & 133 & NADH5 & P. pardus & LEO(African) & Africa & Ropiquet et al. 2015 \\
\hline HQ185549.1 - HQ185550.1 & 2 & NADH5 & P. pardus & orientalis & Caucasus & Rozhnov et al. 2011 \\
\hline HQ185544.1 - HQ185548.1 & 5 & NADH5 & P. pardus & saxicolor & Caucasus & Rozhnov et al. 2011 \\
\hline EF551002.1 & 1 & $\begin{array}{l}\text { Mitochondrion } \\
\text { complete }\end{array}$ & P. pardus & Not specified & China & Lei et al. 2011 \\
\hline
\end{tabular}




\begin{tabular}{|c|c|c|c|c|c|c|}
\hline EF056501.1 & 1 & NADH5 & P. pardus & Not specified & India & Shouche (Unpublished) \\
\hline AY035292.1 & 1 & NADH5 & P. pardus & Melas & Java (Indonesia) & Uphyrkina et al. 2001 \\
\hline AY035280.1 - AY035291.1 & 12 & NADH5 & P. pardus & Shortridgei & $\begin{array}{l}\text { Central Africa (Namibia, } \\
\text { Botswana, Kruger \& Zimbabwe) }\end{array}$ & Uphyrkina et al. 2001 \\
\hline AY035279.1 & 1 & NADH5 & P. pardus & Nimr & $\begin{array}{l}\text { South Arabia (wild animal, } \\
\text { exact location not specified) }\end{array}$ & Uphyrkina et al. 2001 \\
\hline AY035277.1 - AY035278.1 & 2 & NADH5 & P. pardus & Saxicolor & Central Asia (Captive) & Uphyrkina et al. 2001 \\
\hline AY035276.1 & 1 & NADH5 & P. pardus & Sindica & Central Asia (Baluchistan) & Uphyrkina et al. 2001 \\
\hline AY035270.1 - AY035275.1 & 6 & NADH5 & P. pardus & Fusca & India & Uphyrkina et al. 2001 \\
\hline AY035267.1 - AY035269.1 & 3 & $\mathrm{NADH} 5$ & P. pardus & Kotiya & Srilanka & Uphyrkina et al. 2001 \\
\hline AY035264.1 - AY035266.1 & 3 & NADH5 & P. pardus & Delacouri & East Asia (South China) & Uphyrkina et al. 2001 \\
\hline
\end{tabular}




\begin{tabular}{|c|c|c|c|c|c|c|}
\hline AY035262.1 - AY035263.1 & 2 & NADH5 & P. pardus & Japonensis & East Asia (North China) & Uphyrkina et al. 2001 \\
\hline AY035260.1 - AY035261.1 & 2 & NADH5 & P. pardus & Orientalis & Russia & Uphyrkina et al. 2001 \\
\hline KF768352-KF768354 & 3 & NADH5 & P. pardus & Saxicolor & Iran & Farhadinia et al. 2015 \\
\hline EF551004.1 & 1 & $\begin{array}{l}\text { Mitochondrion } \\
\text { complete }\end{array}$ & Uncia uncia & Out Group & China & Wei et al. 2008 \\
\hline EF551003.1 & 1 & $\begin{array}{l}\text { Mitochondrion } \\
\text { complete }\end{array}$ & $\begin{array}{l}\text { Panthera } \\
\text { tigris }\end{array}$ & Out Group & China & Lei et al. 2011 \\
\hline AF385614.1 & 1 & $\begin{array}{l}\text { Mitochondrion } \\
\text { complete }\end{array}$ & P. tigris & Out Group & Africa & Dubach et al. 2005 \\
\hline HM589215.1 & 1 & $\begin{array}{l}\text { Mitochondrion } \\
\text { complete }\end{array}$ & P. tigris & Out Group & China & Zhang et al. 2011 \\
\hline AF385613.1 & 1 & $\begin{array}{l}\text { Mitochondrion } \\
\text { complete }\end{array}$ & P. leo & Out Group & $\begin{array}{l}\text { Brookfield zoo (Exact location } \\
\text { unknown) }\end{array}$ & Dubach et al. 2005 \\
\hline
\end{tabular}




\section{Table 3 (on next page)}

Genetic variation of the Panthera pardus mtDNA from different geographical locations.

Number of samples and number of haplotypes are reported. Haplotype diversity is calculated based on the number of different nucleotides, while nucleotide diversity was obtained from the pairwise distance matrix. Number of segregating sites are reported specifying the number of substitution and if these were transitions or transversions. 
1Table 3. Genetic variation of the Panthera pardus mtDNA from different geographical locations. Number of samples and number of haplotypes are 2reported. Haplotype diversity is calculated based on the number of different nucleotides, while nucleotide diversity was obtained from the pairwise distance matrix. 3 Number of segregating sites are reported specifying the number of substitution and if these were transitions or transversions.

\begin{tabular}{|c|c|c|c|c|c|c|c|c|c|c|}
\hline Sub species & $\begin{array}{l}\text { Geographic } \\
\text { location }\end{array}$ & Accession Number & $\begin{array}{c}\text { No of } \\
\text { samples }\end{array}$ & Haplotypes & $\begin{array}{l}\text { Haplotype } \\
\text { diversity (nt) }\end{array}$ & $\begin{array}{l}\text { Nucleotide } \\
\text { diversity }\end{array}$ & $\begin{array}{l}\text { Segregating } \\
\text { sites }\end{array}$ & Transitions & Transversions & Substitution \\
\hline This study & Pakistan & MK425702-MK425744 & 43 & 3 & $1-3$ & $0.003-0.006$ & 3 & 3 & 0 & 3 \\
\hline P. p. sindica & Pakistan & AY035276.1 & 1 & 1 & NA & NA & NA & NA & NA & NA \\
\hline P. p. saxicolor & Iran & $\begin{array}{l}\text { JX559073.1 - JX559076.1 } \\
\text { HQ185544.1 - HQ185548.1 } \\
\text { AY035277.1 - AY035278.1 } \\
\text { KF768352-KF768354 }\end{array}$ & 14 & 4 & $1-3$ & $0.002-0.004$ & 6 & 6 & 0 & 6 \\
\hline P. p. fusca & India & AY035270.1 - AY035275.1 & 6 & 6 & $2 / 3-6 / 9$ & $0.003-0.01$ & 15 & 15 & 0 & 15 \\
\hline P. p. kotiya & Srilanka & AY035267.1 - AY035269.1 & 3 & 2 & 1 & 0.002 & 1 & 1 & 0 & 1 \\
\hline P. p. orientalis & Russia & $\begin{array}{l}\text { HQ185549.1 - HQ185550.1 } \\
\text { AY035260.1 - AY035261.1 }\end{array}$ & 4 & 3 & $3-6$ & 0.01 & 7 & 7 & 0 & 7 \\
\hline P. p. nimer & Arabia & AY035279.1 & 1 & 1 & NA & NA & NA & NA & NA & NA \\
\hline $\begin{array}{l}\text { P.p.leo } \\
\text { P.p. shortridgei }\end{array}$ & Africa & $\begin{array}{l}\text { KY2922222.1 - KY292277.1 } \\
\text { JF720187.1 - JF720319.1 } \\
\text { AY035280.1 - AY035291.1 }\end{array}$ & 201 & 30 & $1-20 / 23$ & $0.002-0.038$ & 77 & 75 & 2 & 77 \\
\hline P.p. melas & Indonesia & AY035292.1 & 1 & 1 & NA & NA & NA & NA & NA & NA \\
\hline P. p. delacouri & $\begin{array}{l}\text { South } \\
\text { Chinese }\end{array}$ & AY035264.1 - AY035266.1 & 3 & 3 & $2-4$ & $0.003-0.01$ & 6 & 6 & 0 & 6 \\
\hline
\end{tabular}




\begin{tabular}{|c|c|c|c|c|c|c|c|c|c|c|}
\hline P. p. japonensis & $\begin{array}{l}\text { North } \\
\text { Chinese }\end{array}$ & AY035262.1 - AY035263.1 & 2 & 2 & $3 / 5$ & 0.005 & $3-5$ & $3-5$ & 0 & $3-5$ \\
\hline
\end{tabular}

